\title{
Non-Invasive Diagnostics to Measure Physical Properties in High-Level Wastes
}

(Project Number: 73827)

\section{Principal Investigator}

Robert L. Powell

University of California, Davis

Department of Chemical Engineering and Materials Science

One Shields Avenue

Davis, CA 95616-5294

530-752-8779 (phone)

rlpowell@ucdavis.edu

\section{Co-Investigator}

David M. Pfund

Pacific Northwest National Laboratory

P.O. Box 999, MSIN K7-15

Richland, WA 99352

509-375-3879 (phone)

509-375-2806 (fax)

david.pfund@pnl.gov

\section{Graduate Student}

Nihan Dogan, Ph.D. 


\section{Research Objective}

This project addresses the need for a technique that can determine the rheological properties of tank wastes under processing conditions and permit the monitoring and control of slurries during transport. The work consists of applying ultrasonic Doppler velocimetry and using it to measure the viscosity of flowing waste. We will use suspensions that simulate tank waste and will work under realistic flow conditions.

The work will also include a demonstration of a tomographic measurement of solids loading and velocity profiles and an investigation of the utility of this approach in estimating mass flow rate. A tomographic system uses a number of independent line-of-sight measurements to solve the problem of simultaneously measuring the solids loading and velocity profiles within the pipe. Determining mass flow rate and weight percent solids requires knowledge of the speed of sound as a function of loading; questions that will be addressed include effects of the particle size and density distributions.

Finally, this work will investigate the use of ultrasonic techniques to measure sedimentation interface and rate. A tool that could result from successful demonstration could be used to monitor sedimentation progress during in-tank pretreatment and waste processing.

\section{Research Progress and Implications}

This report summarizes work after 18 months of a 3-year project.

A new self-contained ultrasonic Doppler velocimeter (UDV) was designed and built during the first year of the project. The new unit closes the gap between a laboratory experiment and a field-deployable unit instrument for measuring velocity profiles, volumetric flow rates, and viscosities. It combines the UDV instrument, acquisition of pressure and temperature measurements, and real-time calculations of viscosity versus shear rate into one package. New capabilities have been added to make it perform without the need for operator intervention or batch laboratory experiments:

- It is a multiple-frequency instrument (1 MHz, $2 \mathrm{MHz}$ and $5 \mathrm{MHz})$.

- It provides a measure of signal quality at each radial position that is used to improve data analysis.

- It will measure the sound speed of the fluid concurrently with velocity measurement, automatically compensating for temperature and composition variations and eliminating the need for a new calibration when a new fluid is being metered. 
Preliminary tests of the new instrument were performed in fall 2001. The tests revealed the need for modifications to the instrument. The modifications, made during spring 2002, included the following:

- The electronics that drive the ultrasound transducers were improved to increase the signal-tonoise ratio.

- The instrument's computer software was revised to improve the user interface, reduce the amount of post-processing required, and allow the mass production of data.

- The software was tested, errors were corrected, and documentation is being prepared.

The new UDV system will be tested with slurry simulants in our existing flow loop. The loop has been modified to improve operation at higher flow rates with viscous materials. New pressure sensors were purchased and installed for use with the slurries.

A new technique was developed that will allow the construction of fast arrays of ultrasonic transducers for tomography applications. Long-duration pulses are integrated to increase the signal-to-noise ratio. The pulses are encoded with information that allows sharp time resolution and enables many transducers to use the same bandwidth at the same time.

We have met twice with our collaborators from the University of California, Davis. Pacific Northwest National Laboratory personnel visited Davis in January 2002. A graduate student from UC Davis performed experiments in our laboratory during summer 2001.

\section{Planned Activities}

- Diagnostic tests of the new UDV system are scheduled for June 2002.

- Tests of the new UDV system with slurry simulants will be done in August 2002.

- Application of the new long-duration pulse technique to the measurement of time-of-flight through slurries is slated for September 2002. 


\section{Information Access}

Dogan N, RL Powell, MJ McCarthy, R Pappas, DM Pfund, and DM. Sheen. 2002. In-line ultrasonic sensor for characterization of opaque suspensions. Presentation to the ACS National Meeting, Orlando, Florida, April 7-11, 2002(abstract accessible at

http://chemistry.org/portal/PersonalScheduler/EventView.jsp?paper key=204262\&session key= $\underline{34673)}$

Pappas, RA, JA Bamberger, LJ Bond, MS Greenwood, PD Panetta, and DM Pfund. 2001. Ultrasonic Methods for Characterization of Liquids and Slurries. In 2001 IEEE Ultrasonics Symposium Proceedings, Vol. 1, pp. 563-566. Institute of Electrical and Electronics Engineers, Piscataway, New Jersey. 